\title{
Transverse impact performance and finite element analysis of three dimensional braided composite tubes with different braiding layers
}

\author{
Haili Zhou , Dongmei Hu ${ }^{\#}$, Bohong Gu, Baozhong Sun*
}

College of Textiles, Key Laboratory of High Performance Fibers \& Products, Ministry of Education, Donghua University, Shanghai, China, 201620

Center for Civil Aviation Composites, Donghua University, Shanghai, China, 201620

\#: These authors contributed equally

(*: Corresponding author: E-mail: sunbz@ dhu.edu.cn Tel: +86-21-67792782 Fax: +86-21-67792627)

\begin{abstract}
The transverse impact performance of three dimensional (3-D) braided composite tubes has been studied both experimentally and numerically. Three types of braided composite tubes were manufactured by changing the number of braiding layers. The transverse impact test was performed on a modified split Hopkinson pressure bar (SHPB) apparatus under three impact gas pressures. From the tests, impact load, displacement and energy absorbed all increase with the increase of gas pressure. The increase of braiding layers leads to the increase of the impact load and energy absorption, but leads to the decrease of impact displacement. The specific load normalized by the linear density of the tubes also increases with the increment of braiding layers. The results indicated that more braiding layers contributed to higher stiffness. The impact damage modes were matrix crack, fiber breakage and shear bands at the area of impact. From the finite element method (FEM), the stress distribution on the impacted tube was highlighted plus the damage progression during the transverse impact cycles.
\end{abstract}

Keywords: Impulsive loading; matrix composite; fiber reinforced; braiding tube; finite element. 


\section{Introduction}

The growing use of composite tubes as support structures in transport and civil engineering work has increased the interest in stress analysis of cylindrical composite structures $[1,2]$. The growth in use is driven by the advantages offered by composite materials of high strength to weight ratio, high energy absorption, and the ability to be used in extreme conditions and high energy absorption during impact. Most of the current researches so far have been concentrated on plate and beam structures [3-9], whereas only a few on circular tube structures $[1,10,11]$.

The dynamic behaviors of composite tubes have been investigated widely. Tarfaoui et al [12] performed dynamic investigation on the thick glass/epoxy tubular structures both experimentally and numerically. The results reveal that both the scale and the size of the tubes show great effects on the impact response. Kim et al [13] studied the effect of curvature on the response of curved composite structures to dynamic impact loading. The result shows that the maximum impact force increases as the curvature increases. The crush behaviors and energy absorption of composite tubes have been investigated in references $[2,11,14-19]$. From the results, we can find that the micro-structure and geometry have great influence on the impact damage and energy absorption. However, most of the researches mentioned above were focused on the impact behaviors of the composite tubes along axial direction. Recently, the authors of this paper [20-22] have studied the transverse impact deformation and damage behaviors of 3D braided composite tubes. The effects of braiding angle and axial yarns on the damage mechanisms have been investigated. This paper will be focused on the effect of braiding layers on the transverse impact deformation and damage mechanisms.

The split Hopkinson pressure bar (SHPB) apparatus has been used to study dynamic response of composites. For example, Sun et al [23] and Li et al [24] studied dynamic properties of the 3-D composite materials by use of the SHPB. Zhang et al $[6,25]$ used SHPB system to study the transverse impact response of 3-D carbon/epoxy braided composite. Li et al [26, 27] also used SHPB technique to study the 
compressive properties at high strain rates of 3-D five-directional carbon/phenolic braided composites. They showed that the damage and failure patterns differed with high strain rates. G. Subhash et al[28] and A.M. Waas et al[29] also studied the dynamic behaviors of $3 \mathrm{D}$ woven composites. In this paper, a modified SHPB apparatus $[25,30]$ was used to conduct the transverse impact test.

The objective of this study is to investigate the effect of increasing the number of layers on the responses of 3-D braided composite tubes under transverse impact loading. The responses have been studied using both experimental and finite element analysis (FEA) approaches. The load-displacement, energy absorption and damage process were obtained. The damage and energy absorption mechanisms were revealed both from experimental and FEA model.

\section{Experimental approach}

\subsection{Composite tube preparation}

The carbon fiber (T700 from Toray, Japan) was used to braid the circular preforms. The braided preforms were prepared with $1 \times 1$ four step circular braiding process. The yarn carriers were arranged in a circular outline on the machine bed to braid a tubular perform as shown in Figure 1. The yarn carriers took the form of $(m \times n)$, where $m$ is the number of carriers in the circumferential direction and $n$ is the number of carriers in the radial direction. The preforms were also braided on a circular mandrel to further enhance their circular shape. Three kinds of preforms were braided depending on the number of radial layers used $(n)$. Two-layer $(2 L)$, three-layer $(3 L)$ and four-layer $(4 L)$ preforms were braided as shown in Figure 1.

Three-dimension composite tubes were manufactured from the braided preforms by injecting epoxy resin with the use of vacuum assisted resin transfer molding (VARTM) process. Resorcinol epoxy resin was supplied by Changshu Jiafa® Chemical Co. Ltd, China. It was prepared by mixing together with a curing agent at a ratio of 100:80, and followed by vacuuming process to remove air bubbles.

Impregnation process was done at a temperature of $50^{\circ} \mathrm{C}$ to allow faster movement of 
resin by lowering its viscosity. Curing process was done as follows: $90^{\circ} \mathrm{C}$ for 2 hours, $110^{\circ} \mathrm{C}$ for 1 hour and finally $130^{\circ} \mathrm{C}$ for 4 hours, after which the samples were left to cool to room temperature over a period of 24 hours.

The samples were cut into testing length of $150 \mathrm{~mm}$ with the use of a water cooled diamond cutter. The specifications of braided composite tubes are shown in Table 1.

\subsection{Transverse impact tests}

As is shown in Figure 2(a), a modified split Hopkinson pressure bar (SHPB) apparatus was used to conduct the transverse impact test of the 3-D braided composite tubes. The sample was fixed on the apparatus by a sample holder with a testing length of $100 \mathrm{~mm}$. The working principle of the SHPB apparatus is shown in Figure 2(b). The diameters of the striker bar and incident bar were $30 \mathrm{~mm}$ and their lengths were $400 \mathrm{~mm}$ and $1800 \mathrm{~mm}$, respectively. When the striker bar impacted the incident bar, an elastic stress wave was generated, and spread along the incident bar. The stress wave duration is equal to the time needed by the wave to make a round-trip in the striker. When the wave reached the surface between the incident bar and the sample, it was divided into two parts. One part was reflected back to the incident bar and the other one went through the sample. When the reflective stress wave got the other free surface of the incident bar, it would be reflected again to be another strike stress wave. Three impact gas pressures of $0.2 \mathrm{MPa}, 0.4 \mathrm{MPa}$ and $0.6 \mathrm{MPa}$ were used for the tests giving rise to three corresponding velocities of $7 \mathrm{~m} / \mathrm{s}, 12 \mathrm{~m} / \mathrm{s}$ and $17 \mathrm{~m} / \mathrm{s}$.

The parameters of the bars are modulus $(E)$, cross-sectional area $(A)$ and its density $(\rho)$. These parameters are used to describe the equations of the load $(P(t))$, displacement $(\mu(t))$, velocity of the wave $\left(C_{o}\right)$ plus the energy absorption $(W)$ during the SHPB impact event. The equations are:

$$
\begin{aligned}
& P(t)=E A\left[\varepsilon_{I}(t)+\varepsilon_{R}(t)\right] \\
& \mu(t)=C_{o} \int_{0}^{t}\left[\varepsilon_{I}(t)-\varepsilon_{R}(t)\right] d t \\
& C_{o}=\sqrt{E / \rho}
\end{aligned}
$$




$$
W=\int_{0}^{t} \frac{1}{2} P(t) \mu(t) d t=\frac{1}{2} E A C_{o} \int_{0}^{t}\left[\varepsilon_{1}^{2}(t)-\varepsilon_{R}^{2}(t)\right] d t
$$

where $\varepsilon_{I}(t)$ and $\varepsilon_{R}(t)$ are the incident and reflected strain gauge signals respectively. The load-displacement curves of the 3-D braided composite tube samples under transverse impact was attained with the modified SHPB apparatus in order to investigate the impact energy absorption and to validate the FEM calculated outcome.

\section{Finite element analysis}

\subsection{Material model}

The microstructure models shown in Figure 3 were developed to represent the 3-D braided composite tube with finite element method [31, 32]. The composite tube was composed of matrix and reinforcement. The reinforcement was established based on the trajectories of the braiding yarns in the preform. The braiding yarns were considered as transversely isotropic unidirectional composite consisting of resin and fiber tow. The properties of the resin and fiber tow are listed in Table 2 and Table 3, separately. The mechanical properties of the braiding yarn were calculated by the mixture model[33]:

$$
\begin{aligned}
& E_{11}=\delta_{f} E_{11}^{f}+\delta_{m} E_{m} \\
& E_{22}=E_{33}=E_{m} /\left[1-\sqrt{\delta_{f}}\left(1-E_{m} / E_{22}^{f}\right)\right] \\
& v_{12}=v_{13}=\delta_{f} v_{12}^{f}+\delta_{m} v_{m} \\
& v_{23}=\delta_{f} v_{23}^{f}+\delta_{m} v_{m} \\
& G_{12}=G_{13}=G_{m} /\left[1-\sqrt{\delta_{f}}\left(1-G_{m} / G_{12}^{f}\right)\right] \\
& G_{23}=G_{m} /\left[1-\sqrt{\delta_{f}}\left(1-G_{m} / G_{23}^{f}\right)\right] \\
& \delta_{f}+\delta_{m}=1
\end{aligned}
$$

where $E^{f}{ }_{11}, E^{f}{ }_{22}, v^{f}{ }_{12}, v^{f}{ }_{23}, G_{12}^{f}$ and $G_{23}^{f}$ are longitudinal modulus, transverse modulus, Poisson's ratio and shear modulus of the carbon fiber, respectively; $E_{m}, v_{m}$ and $G_{m}$ are the elastic modulus, Poisson's ratio and shear modulus of the resin, 
respectively; $E_{11}, E_{22}, E_{33}, v_{12}, v_{13}, v_{23}, G_{12}, G_{13}$ and $G_{23}$ are the equivalent longitudinal modulus, transverse modulus, Poisson's ratio and shear modulus of the braiding yarn, respectively; $\delta_{f}$ is the fiber packing factor in a yarn and can be defined as:

$$
\varepsilon=\frac{\pi D_{y}^{2}}{4 \Omega}
$$

where

$$
D_{y}=\sqrt{\frac{4 \lambda}{\pi \rho}}
$$

is the diameter of a fiber tow ( $\mathrm{mm}$ ) and it is calculated by use of the yarn linear density $\lambda(\mathrm{g} / \mathrm{m})\left(\lambda=\operatorname{Tex}_{\mathrm{y}} / 1000\right)$ and the fiber density $\rho\left(\mathrm{g} / \mathrm{cm}^{3}\right) . \Omega$ is the equivalent area of yarn cross section.

The resin was considered to be isotropic material. Hill's anisotropic plasticity model [34]was used to definite the yield properties of the yarn tows. The matrix was assumed to obey the $\mathrm{J} 2$-isotropic hardening plasticity theory [35] . The tensile stress strain curve of epoxy resin can be found in paper[36].

The dynamic failure models were based on the ductile failure and the shear failure models which allowed the removal of the damage elements [37]. The progressive stiffness degradation follows the damage evolution law based on the energy dissipated during the damage process. The diminution of stress is affected by a scalar damage variable, $D$ computed in terms of individual damage variables, $d_{i}$. In this paper, the damage evolution definition was based on energy dissipated during the damage process. Once the damage initiation criterion is met, the damage variable increases according to

$$
d_{i}=\frac{\stackrel{\cdot}{\bar{\varepsilon}}^{p l}}{\bar{u}_{f}^{p l}}=\frac{{\stackrel{\cdot}{u_{f}}}_{f}}{\bar{u}_{f}}
$$

where the equivalent plastic displacement at failure is computed as $\bar{u}_{f}^{p l}=\frac{2 G_{f}}{\sigma_{y 0}}$ and 
$\sigma_{y 0}$ is the value of the yield stress at the time when the failure criterion is reached.

The fracture energy, $G_{f}$ can be specify.

At any given time during the analysis progression, the stress tensor $(\sigma)$ follows the scalar damage equation

$$
\sigma=(1-D) \bar{\sigma}
$$

where $\bar{\sigma}$ is the undamaged effective stress tensor. As $D$ increases to $D_{\max }$, the elements are removed.

\section{Transverse impact tests model}

The transverse impact tests were modeled in the commercial FEA software ABAQUS. The incident bar was regarded as elastic material. C3D8R element was chosen to model the braided yarns and the incident bar. C3D4 element was used to model the resin which had complex shape, and especially the interface between resin and braiding yarns. Figure 4 (a) shows finite element model. The approximate global size of seed was $0.4 \mathrm{~mm}$. The total number of the elements was about 2,400,000 for 2-layer tube, 1,800,000 for 3-layer tube and 2,400,000 for 4-layer tube. Figure 4 (b) shows the boundary conditions where the incident bar was restricted only to impact direction and the composite tube was fixed on both ends. The interface between the braiding yarns and the matrix was model by a tied constraint. An input wave was set on one end of the incident bar.

\section{Results and discussions}

\subsection{Load-displacement curves}

The influence of the number of layers on the response of 3-D braided composite tubes under transverse impact loading has been captured with the use of load-displacement curves. Both the experimental and FEM results have been highlighted. Figures 5-7 show the load-displacement curves under different impact gas pressure of $0.2 \mathrm{MPa}$, $0.4 \mathrm{MPa}$ and $0.6 \mathrm{MPa}$, respectively. In all the curves, fluctuation of the load can be observed from the first cycle to the fourth cycle. As the cycles increased, the peak 
load reduced. The reason is that during an impact cycle, part of the stress wave passed through the sample and part of it reflected back the incident bar. This reduced the energy of the next impact cycle thus the peak load of the preceding cycle was lower. The phenomenon means that the peak load decreased throughout the entire repeating process due to the energy dissipation.

Figure 5 shows the load-displacement curve of the 3-D braided composite tube impacted with a gas pressure 0.2MPa. Figure 5(a) shows the experimental results while Figure 5(b) shows the FEM results. From the comparison, it can be seen that as the number of layers increased from 2 to 4, the peak load increased. On the contrary, as the number of layers increased, the displacement reduced. This is due to that both the interlacing times of yarns through the thickness of the tube and the fiber volume fraction increased as the number of layers increased, which enhanced the deformation resistance. The other observation was the reduction of the peak load with the increase in cycles, where the first cycle had the highest peak load and reduced to the fourth cycle having the lowest peak load. This same trend was observed from both the experimental and FEM results.

Figure 6 and 7 show the curves obtained by impacting the specimens with a gas pressure of $0.4 \mathrm{MPa}$ and $0.6 \mathrm{MPa}$, respectively. The same trend obtained with $0.2 \mathrm{MPa}$ gas pressure was also observed. The experimental and FEM results were in good agreement both in terms of the peak load and the displacement showing that the developed models were able to predict transverse impact results. It was noted that the load from FEM showed a little higher and the displacement from FEM showed a little lower than those from experiment. This is because that the defects like holes, cracks and interface in the actual sample were ignored in the model.

\subsection{Specific load}

From the parameters of the specimens in Table 1, the tubes have different volume fractions and linear densities. For this reason, there is a necessity to normalize the results for better comparison. A parameter 'specific load' $\left(L_{S}\right)$ was proposed which 
characterized the peak load divided by the linear density of the tubes.

$$
L_{s p}=\frac{L_{p}}{\rho_{t}}
$$

where $L_{s p}$ is the specific load, $L_{p}$ is the highest peak load while $\rho_{t}$ is the linear density of the 3-D braided composite tube. Similar parameter was used by Wang et al [38] in evaluating the tube energy absorption capacity during transverse impact event.

Figure 8 shows the specific load verses impact pressure curves. It can be seen that as the impact pressure increased, the specific load increased for all the tubes with different layers. For a specific impact pressure, the specific load increased with the increase in the number of layers. This shows that the specific load increases with the increment in the thickness of the 3-D braided composite tube.

\subsection{Displacement-time curves}

Figures 9-11 show the displacement-time curves of transverse impact loading on the 3-D braided composite tubes at $0.2 \mathrm{MPa}, 0.4 \mathrm{MPa}$ and $0.6 \mathrm{MPa}$ gas pressures respectively. Figures 9(a), 10(a), 11(a) show the results obtained experimentally while Figures 9(b), 10(b), 11(b) show results obtained from FEM calculation. All the curves exhibit the same trend. The displacement increased with time during the impact cycle and remain constant during the reflect wave part.

From Figures 9-11, it can be seen that the displacement increases with the time and impact gas pressure increase. It can also be observed that with the increase in number of layers, the displacement decreases. This can be explained by the micro-structures of the tubes with different braiding layers. With more number of layers, the angle of the yarns alternating between inner and outer diameters increased as shown in Figure 1 , which increased the interlacing times of yarns through the thickness improving the integrity of composite tube. Meanwhile, the fiber volume fraction increased as the number of layers increased. Thus, the rigidity was higher for tube with more number of braiding layers. Comparing Figures 9-10 (a) and (b), it is seen that both results were in good agreement in terms of displacement and the trend of the curves. This 
confirms that the developed model was able to predict the response of the 3-D braided composite tube.

\subsection{Energy absorption}

Figure 12 compares the energy absorption of 3-D braided composite tubes with different layers under different impact gas pressures. The energy absorption can be evaluated from the integral of the load-displacement curves. It can be seen that for all the impact gas pressures, the 4-layer tubes absorbed higher energy followed by 3-layer tubes and the least was the 2-layer tubes. This could be explained in terms of volume fraction. The 4-layer tube had the highest value. In addition, it can be seen that with the increase in impact gas pressure, the amount of energy absorbed also increases. This was because at higher gas pressure, higher velocity was achieved delivering higher energy stress wave to impact the sample.

\subsection{Yarn stress distribution at the area of impact}

During transverse impact event, different parts of the 3-D braided composite tube undergo different stress magnitude and direction. The impact side was under compression while the non-impact side was under tension. To confirm this assumption, the FEM model was sectioned at the area of impact and the stress of the braiding yarns highlighted. Figure 13 shows the stress distribution of the braiding yarns at the area of impact. From Figures 13, it can be seen that the yarns on the impact side were under compression while the ones on the non-impacted side were under tension. This is clearly seen in the attached stress-time curves.

Figure 13 (a) shows the yarn stress on the 2-layer braided tube where its cross-section contains four yarns at the area of impact. Two yarns, 1 and 2, were under compression while yarns, 3 and 4, were under tension as shown by the attached stress-time curves. Figure 13 (b) shows the stress distribution in the 3-layer braided composite tube and it contains five yarns in its cross-section. It can be seen that, yarns 1 and 2 were under compression and yarn 3 was on a neutral point while yarns 4 and 5 were under tension as shown from stress-time curves. Figure 13 (c) shows the cross-section of the 4-layer 
braided composite tube and the same conclusion can be reached. It contains six yarns of which the three yarns near the impact area were under compression while the three yarns away from the impact area were under tensional stress.

From Figures 13(a)-(c), we can find that the stress of impact point decreased to a low value for all of the three kinds of structures after around $1000 \mu \mathrm{s}$. For 2 layers tube, fiber breakage occurred in the impact point and then broke off in both sides. The impact point almost lost its bearing capacity. However, for 3 and 4 layers tubes, due to more interlacing yarns through the wall thickness, the impact point had higher resistance to damage. The stress value was kept in a high level. Especially for 4 layers tube with compact structure, the curve was kept in a stable value.

\subsection{Stress propagation on the tube}

The experimental damage can only be observed after the final impact cycle. The FEM calculation provides an opportunity to access the damage after every single impact cycle. Figure 14 has been used to illustrate the damage development during the four cycles of the transverse impact loading on the 3-D braided tubes. 2-layer braided composite tube under $0.2 \mathrm{MPa}$ impact gas pressure has been used to explain the stress propagation.

The tube has been opened up to clearly show how the stress was distributed during the impact. Figure 14 shows the 2-layer braided tube that has been opened up. Figure 14 (a) shows the outer surface and inner surface. The impact area on the outer surface was under compression as shown while it was under tension on the inner surface. Because of flattening of the impact section, the sides of the impact area were under tensile stress. The stress spread along the tube from the impacted area to the clamped position. On the clamped position, the top part was under tensile stress while the sides were under compression stress which was observed in both outer surface and the inner surface. The other parts of the tube were under equilibrium.

Figure 14 (b) shows the four cycles of transverse impact loading on the tube. Both the impacted outer surface and non-impacted inner surface have been shown. It can be 
seen that as the number of impact cycles increased, the stress along the tube was amplified. While most parts of the tube were under tension stress, some parts were under compression stress like the impacted region and the parts surrounding the impacted region on the rear side. When the entire tube reached critical stress, failure occurred in terms of perforation. At this point the stress in other parts of the tube returns to zero as shown in the Figure14 (b).

\subsection{Development of damage and deformation}

In order to show the different impact damage of 3-D braided composite tube with different layers, the deformation processes under impact gas pressure of $0.6 \mathrm{MPa}$ are shown in Figures 15 (a)-(c).

The spatial distribution of yarn tows in the composite tube spirals around the tube alternating between inner and outer surfaces. The yarns proportion through thickness increased with the increment of braiding layers, as shown in Figure 1. For 2-layer tube, the yarns proportion through thickness was lower which led to faster stress propagation along the axial direction of the tube. During the first two stress wave cycles, the dent on the impact area was extended to the surrounding regions with a slight damage. After the third cycle, star shape crack damage started from the center of the impact area leading to the whole impact area being perforated during the fourth cycle, losing its loading ability.

However, for 3-layer and 4-layer braided tubes, the higher proportion of yarns in the through thickness direction prevented the propagation of deformation. Instead of damage in the center of the impact area, the whole impact area was dented and clear shear bands were formed around the region during the last three cycles.

\subsection{Damage morphology and failure modes}

Figure 16 shows the damage morphologies of the impacted side of the 3-D braided composite tube with different layers under various impact gas pressures. Figure 16 also compares the experimental damage morphology with the damage results obtained from the FEM calculation. There are a number of observations that can be identified 
in Figure 16.

First, as the impact gas pressure increased from $0.2 \mathrm{MPa}$ to $0.6 \mathrm{MPa}$, the damage area increased in all the samples. This was because higher impact gas pressure delivered higher impact energy which caused more damage. Secondly, under the same impact gas pressure, the damage area was reduced with the increase in the number of layers. This can be attributed to the fact that with the increase in number of layers, the 3-D braid composite tube damage resistance increased. Thirdly, in comparing the experimental results with the FEM calculated results, it can be seen that there was a fairly good agreement of transverse impact deformation and damage morphology. This further validates that the developed model was able to predict the transverse impact behavior of the braided composite tube.

The main damage modes were matrix crack especially under lower impact gas pressures, fiber breakage, shearing at the area of impact and shattering failure especially for the two layer tube under high impact gas pressure. The fiber breakage and the shear damage have also been captured clearly with the FEM calculation. It should be noted that the 3-D braided composite tubes displayed a high delamination resistance, and therefore, damage was localized mainly to the area of impact.

\section{Conclusions}

This paper presents the transverse impact behaviors of 3-D braided composite tubes with three different braiding layers. A microstructure model was established based on the braided composite architecture for finite element calculation. The impact damage and stress distribution were highlighted numerically to analyze the damage mechanisms. Damage analyses showed that the impact load and energy absorbed increased, but the displacement decreased as the braiding layers increased. The stress distribution through thickness on the impact area varied, the impact side was under compression while the non-impacted side was under tension. The stress distributions in most parts were under tensile stress, while other parts were under compression stress. The failure mode was different for tubes with different braiding layers. For 
2-layer tube, the damage with a star shape started from the center of the impact area and which perforated eventually. However, for 3-layer and 4-layer tubes, the damage mainly focused on the surrounding regions of the impact area with the formation of shear bands. This study has significant value in the structural design of 3D circular braided composite tube. The research method could also be applied in the analysis of other textile composites.

\section{Acknowledgements}

The authors acknowledge the financial supports from the Chang Jiang Scholars Program and National Science Foundation of China (Grant Number 51675095 and 11572085). The financial supports from Foundation for the Fok Ying-Tong Education Foundation (Grant No. 141070), Shu-Guang project (Grant No. 14SG31) supported by Shanghai Municipal Education Commission and Shanghai Education Development Foundation, the Fundamental Research Funds for the Central Universities of China and DHU Distinguished Young Professor Program are also gratefully acknowledged.

\section{References}

1. Li, S., et al., Modelling transverse cracking damage in thin, filament-wound tubes subjected to lateral indentation followed by internal pressure. International Journal of Mechanical Sciences, 2005. 47(4-5): p. 621-646.

2. $\mathrm{Wu}, \mathrm{X}$., et al., Axial compressive deformation and damage of four-step 3-D circular braided composite tubes under various strain rates. The Journal of The Textile Institute, 2016: p. 1-17.

3. $\mathrm{Gu}, \mathrm{B}$. and J. $\mathrm{Xu}$, Finite element calculation of 4-step 3-dimensional braided composite under ballistic perforation. Composites Part B: Engineering, 2004. 35(4): p. 291-297.

4. Gu, B., A microstructure model for finite-element simulation of 3D rectangular braided composite under ballistic penetration. Philosophical Magazine, 2007. 87(30): p. 4643-4669.

5. D., L.J., et al., Effect of microscopic damage events on static and ballistic impact strength of triaxial braid composites. Composites Part A: Applied Science and Manufacturing, 2009. 40(12): p. 1846-1862.

6. Zhang, Y., et al., Transverse impact behaviors of four-step 3-D rectangular braided composites from unit-cell approach. Journal of Reinforced Plastics and Composites, 2012. 31(4): p. 233-246.

7. Shi, Y., et al., An experimental investigation on the low-velocity impact behavior of 3D five-directional braided composites. Polymers for Advanced Technologies, 2014. 25(12): p. 1386-1390. 
8. Zhang, W., B. Gu, and B. Sun, Transverse impact behaviors of 3D braided composites T-beam at elevated temperatures. Journal of Composite Materials, 2016.

9. Hao, A., et al., Dynamic properties of 3-D orthogonal woven composite T-beam under transverse impact. Composites: Part A, 2008. 39: p. 1073-1082.

10. Karbhari, V.M., et al., Post-impact crush of hybrid braided composite tubes. International Journal of Impact Engineering, 1999. 22: p. 419-433.

11. Zeng, T., D. Fang, and T. Lu, Dynamic crashing and impact energy absorption of $3 D$ braided composite tubes. Materials Letters, 2005. 59(12): p. 1491-1496.

12. Tarfaoui, M., et al., Scale and Size Effects on Dynamic Response and Damage of Glass/Epoxy Tubular Structures. Journal of Composite Materials, 2006. 41(5): p. 547-558.

13. Seung Jo Kim, N.S. Goo, and T.W. Kim, The effect of curvature on the dynamic response and impact-induced damage in composite laminates. Composites Science and Technology, 1997. 51: p. 763-773.

14. Siromani, D., J. Awerbuch, and T.-M. Tan, Finite element modeling of the crushing behavior of thin-walled CFRP tubes under axial compression. Composites Part B: Engineering, 2014. 64: p. 50-58.

15. Kim, J.-S., H.-J. Yoon, and K.-B. Shin, A study on crushing behaviors of composite circular tubes with different reinforcing fibers. International Journal of Impact Engineering, 2011. 38(4): p. 198-207.

16. V.M., K. and H. J.E., Rate and architecture effects on progressive crush of braided tubes. Composite Structures, 1998. 43: p. 93-108.

17. Kathiresan, M., K. Manisekar, and V. Manikandan, Crashworthiness analysis of glass fibre/epoxy laminated thin walled composite conical frusta under axial compression. Compos. Struct., 2014. 108: p. 584.

18. Chiu, L.N.S., et al., Crush responses of composite cylinder under quasi-static and dynamic loading. Composite Structures, 2015. 131: p. 90-98.

19. $\mathrm{Wu}, \mathrm{X} ., \mathrm{B} . \mathrm{Gu}$, and B. Sun, Comparisons of axial compression behaviors between four-directional and five-directional braided composite tubes under high strain rate loading. Journal of Composite Materials, 2016.

20. Zhou, H., et al., Finite element analyses on transverse impact behaviors of 3-D circular braided composite tubes with different braiding angles. Composites Part A: Applied Science and Manufacturing, 2015. 79: p. 52-62.

21. Zhou, $\mathrm{H}$., et al., Experimental and numerical investigation of the transverse impact damage and deformation of 3-D circular braided composite tubes from meso-structure approach. Composites Part B: Engineering, 2016. 86: p. 243-253.

22. Zhou, H., B. Sun, and B. Gu, Responses of $3 D$ four-directional and five-directional circular braided composite tubes under transverse impact. International journal of crashworthiness, 2016. 21(4): p. 353-366.

23. Sun, B., D. Hu, and B. Gu, Transverse impact damage and energy absorption of 3-D multi-structured knitted composite. Composites Part B: Engineering, 2009. 40(6): p. 572-583.

24. Li, D.-S., et al., Split Hopkinson Pressure Bar Testing of 3D Multi-axial Warp Knitted Carbon/Epoxy Composites. Composites Part B: Engineering, 2015. 
25. Zhang, Y., B. Sun, and B. Gu, Experimental characterization of transverse impact behaviors of four-step 3-D rectangular braided composites. Journal of Composite Materials, 2012. 46(24): p. 3017-3029.

26. Li, D.-S., et al., High strain rate behavior and failure mechanism of three-dimensional five-directional carbon/phenolic braided composites under transverse compression. Composites Part B: Engineering, 2011. 42(2): p. 309-317.

27. Li, D., Z. Lu, and D. Fang, Longitudinal compressive behavior and failure mechanism of three-dimensional five-directional carbon/phenolic braided composites at high strain rates. Materials Science and Engineering: A, 2009. 526(1-2): p. 134-139.

28. Walter, T.R., et al., Damage modes in 3D glass fiber epoxy woven composites under high rate of impact loading. Composites Part B: Engineering, 2009. 40(6): p. 584-589.

29. Pankow, M., et al., Split Hopkinson pressure bar testing of 3D woven composites. Composites Science and Technology, 2011. 71(9): p. 1196-1208.

30. Baozhong, S., H. Dongmei, and G. Bohong, Transverse impact damage and energy absorption of 3-D multi-structured knitted composite. Composites Part B: Engineering, 2009. 40(6): p. 572-583.

31. Diansen, L., et al., Finite element modeling of mechanical properties of $3 D$ five-directional rectangular braided composites. Composites Part B: Engineering, 2011. 42(6): p. 1373-1385.

32. Xiao, X., H.G. Kia, and X.-J. Gong, Strength prediction of a triaxially braided composite. Composites Part A: Applied Science and Manufacturing, 2011. 42(8): p. 1000-1006.

33. Pan, Z., B. Gu, and B. Sun, Thermo-mechanical behaviors of 3-D braided composite material subject to high strain rate compressions under different temperatures. Mechanics of Advanced Materials \& Structures, 2014: p. 00-00.

34. R., H., On discontinuous plastic states, with special reference to localized necking in thin sheets. Journal of the Mechanics and Physics of Solids, 1952. 1(1): p. 12.

35. Huang, H. and A.M. Waas, Compressive response of Z-pinned woven glass fiber textile composite laminates: Modeling and computations. Composites Science and Technology, 2009. 69(14): p. 2338-2344.

36. Gilat, A., R.K. Goldberg, and G.D. Roberts, Experimental study of strain-rate-dependent behavior of carbon/epoxy composite. Composites Science and Technology, 2002. 62(10-11): p. 1469-1476.

37. Wan, Y., Y. Wang, and B. Gu, Finite element prediction of the impact compressive properties of three-dimensional braided composites using multi-scale model. Composite Structures, 2015. 128: p. 381-394.

38. Wang, Y., et al., Experimental behavior of cement filled pipe-in-pipe composite structures under transverse impact. International Journal of Impact Engineering, 2014. 72: p. 1-16. 
Table 1 Specifications of braided composite tubes

\begin{tabular}{ccccccc}
\hline $\begin{array}{c}\text { Number } \\
\text { of layers }\end{array}$ & $m \times n$ & $\begin{array}{c}\text { Braiding } \\
\text { angle }\left(^{\circ}\right)\end{array}$ & $\begin{array}{c}\text { Inner } \\
\text { diameter } \\
\left(d_{i}\right)\end{array}$ & $\begin{array}{c}\text { Outer } \\
\text { diameter } \\
\left(d_{o}\right)\end{array}$ & $\begin{array}{c}\text { Volume } \\
\text { fraction }\end{array}$ & $\begin{array}{c}\text { Linear } \\
\text { density } \\
(\%)\end{array}$ \\
\hline 2L & $32 \times 2$ & 30 & 20.5 & 24 & 41.42 & 0.17881 \\
3L & $32 \times 3$ & 30 & 20.5 & 25 & 43.30 & 0.2129 \\
$4 \mathrm{~L}$ & $32 \times 4$ & 30 & 20.5 & 26 & 45.00 & 0.26821 \\
\hline
\end{tabular}

Table 2 Properties of resin

\begin{tabular}{ccccc}
\hline Resin & $E_{m}(\mathrm{GPa})$ & $G_{m}(\mathrm{GPa})$ & $v_{m}$ & $\rho\left(\mathrm{g} / \mathrm{cm}^{3}\right)$ \\
\hline Epoxy & 2.4 & 0.89 & 0.35 & 1.13 \\
\hline
\end{tabular}

Table 3 Properties of fiber tow

\begin{tabular}{cccccccc}
\hline $\begin{array}{c}\text { Fiber } \\
\text { tow }\end{array}$ & $\begin{array}{c}E_{11} \\
(\mathrm{GPa})\end{array}$ & $\begin{array}{c}E_{22}=E_{33} \\
(\mathrm{GPa})\end{array}$ & $\begin{array}{c}G_{12}=G_{13} \\
(\mathrm{GPa})\end{array}$ & $\begin{array}{c}G_{23} \\
(\mathrm{GPa})\end{array}$ & $v_{12}=v_{13}$ & $v_{23}$ & $\begin{array}{c}\rho \\
\left(\mathrm{g} / \mathrm{cm}^{3}\right)\end{array}$ \\
\hline $\mathrm{T} 700-12 \mathrm{k}$ & 230 & 14 & 9 & 5 & 0.25 & 0.3 & 1.80 \\
\hline
\end{tabular}

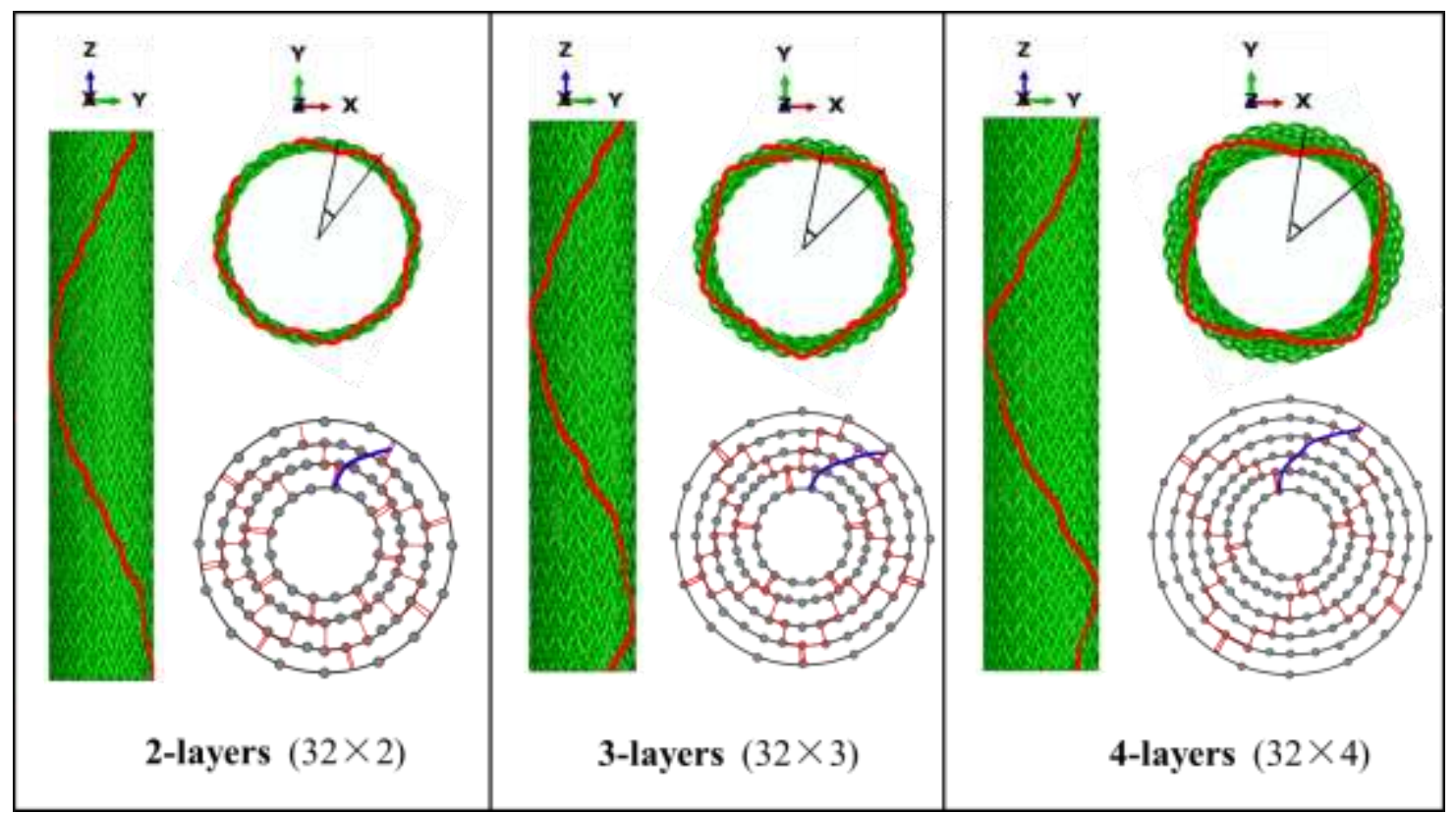

Figure 1: Yarn carrier arrangement on the machine bed and the path of one yarn in the preform 


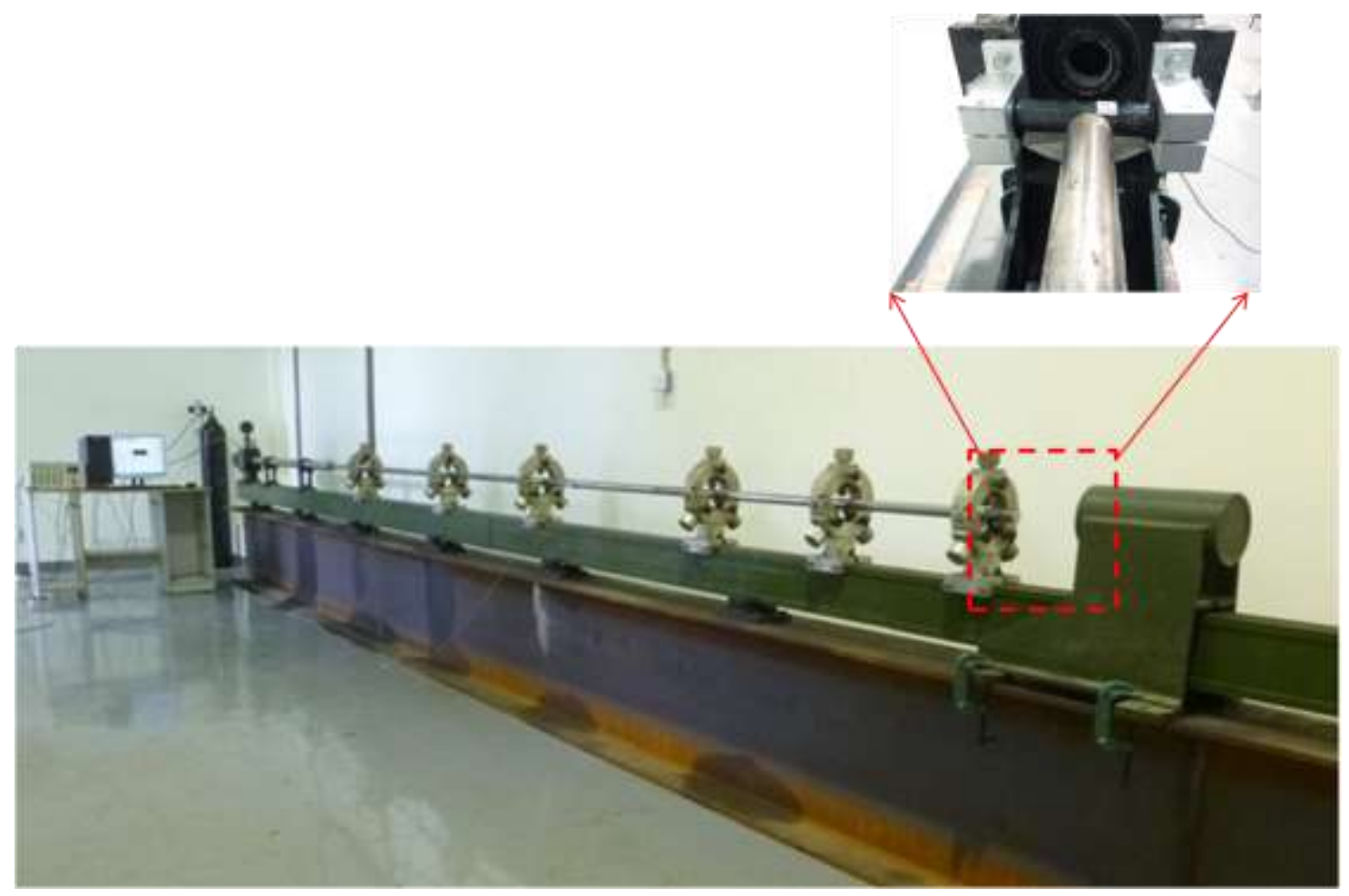

(a)
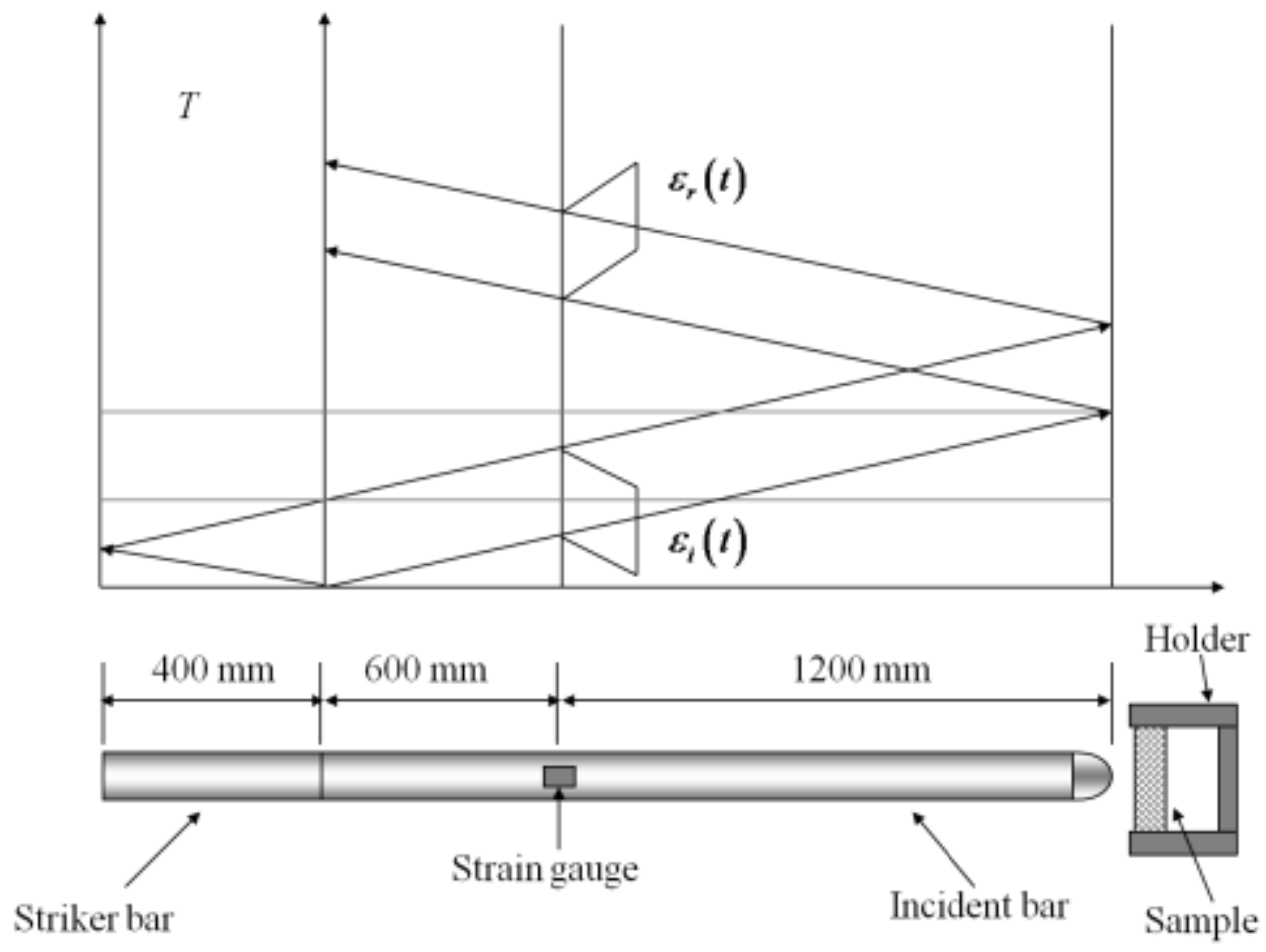

(b)

Figure 2: (a) The modified SHPB setup; (b) The test principle of SHPB 


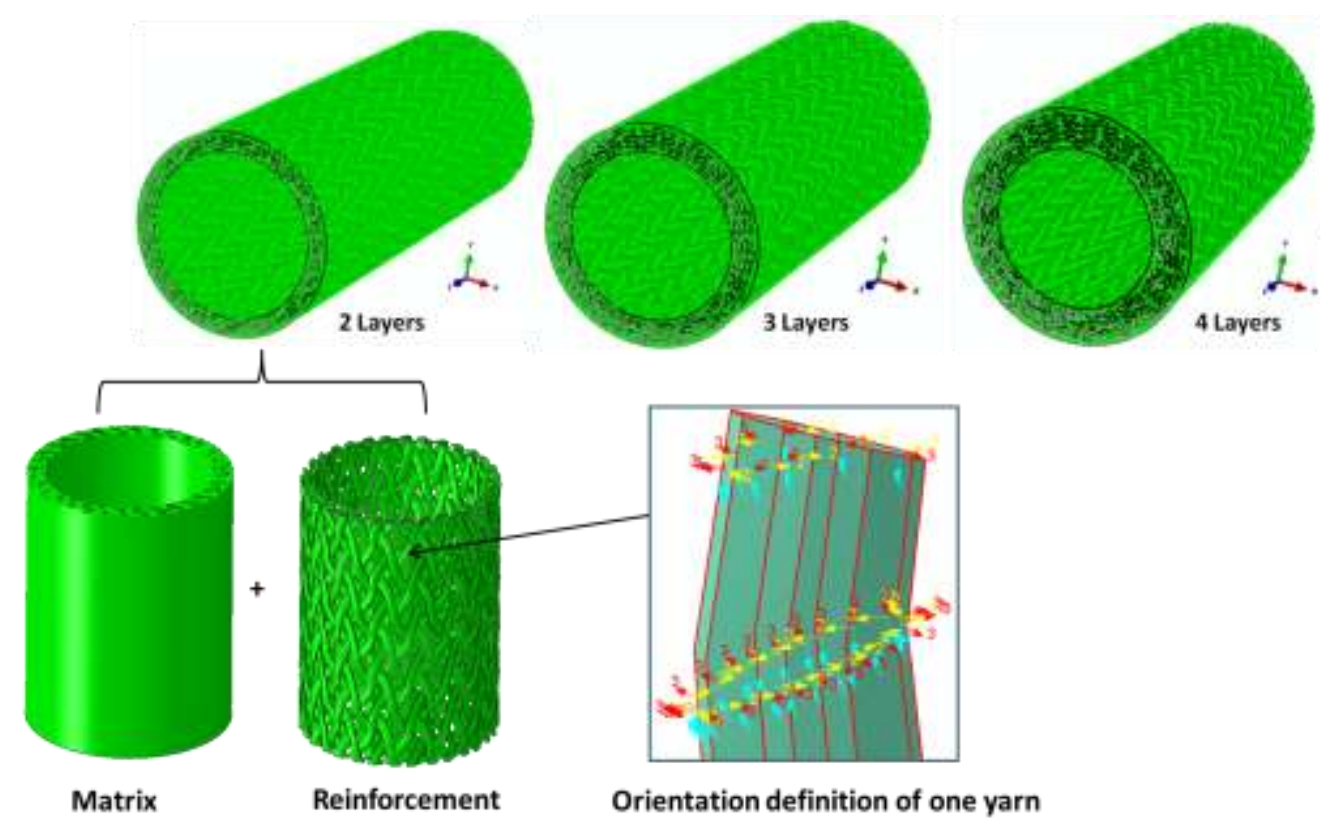

Figure 3: Microstructure model

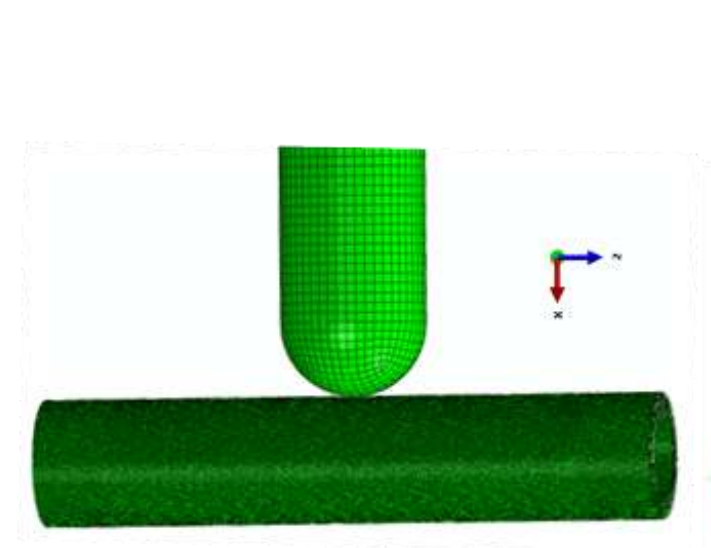

(a)

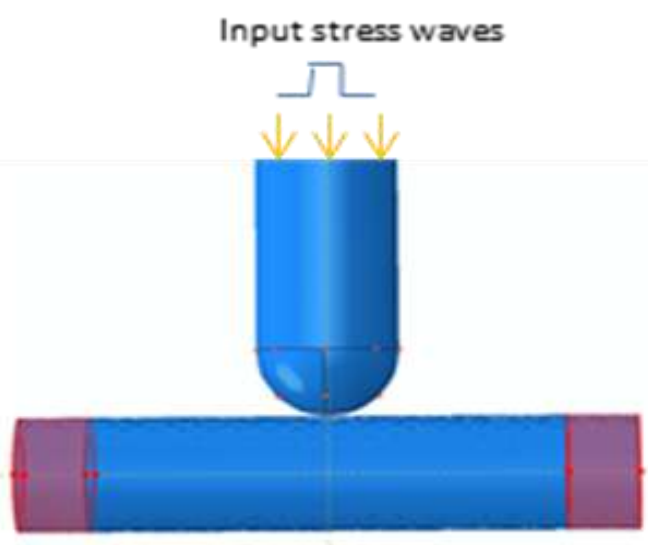

(b)

Figure 4 Finite element model: (a) mesh scheme used (b) boundary conditions 


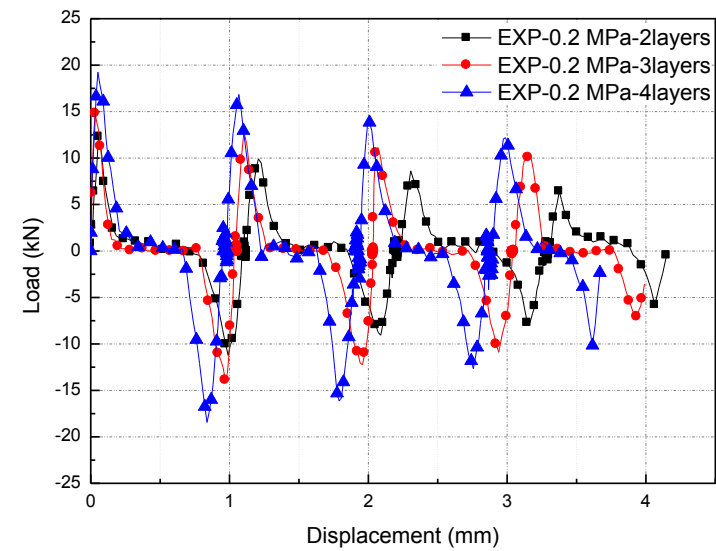

(a)

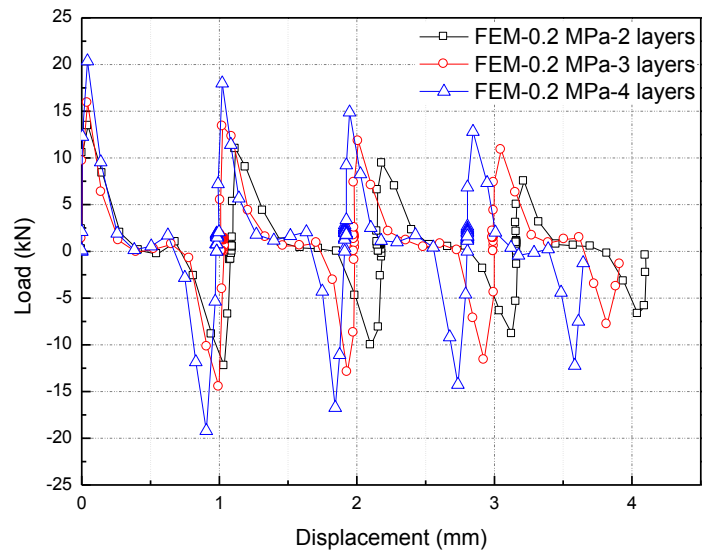

(b)

Figure 5: load-displacement curves under 0.2MPa (a) Experiment (b) FEM

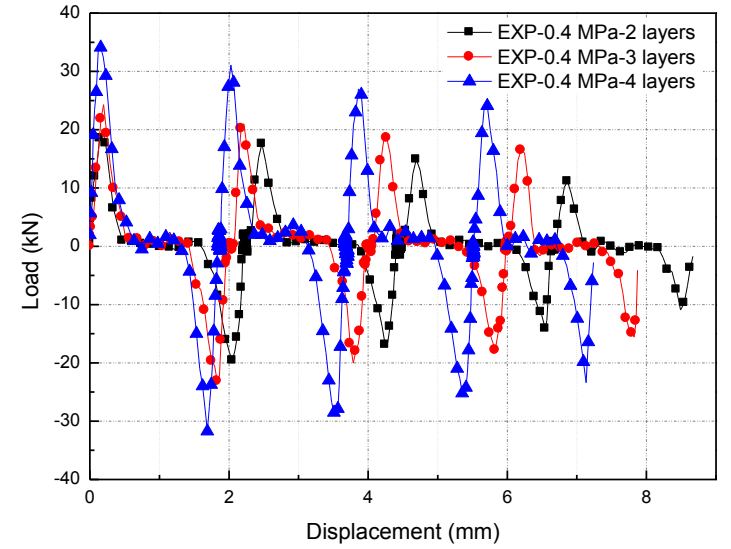

(a)

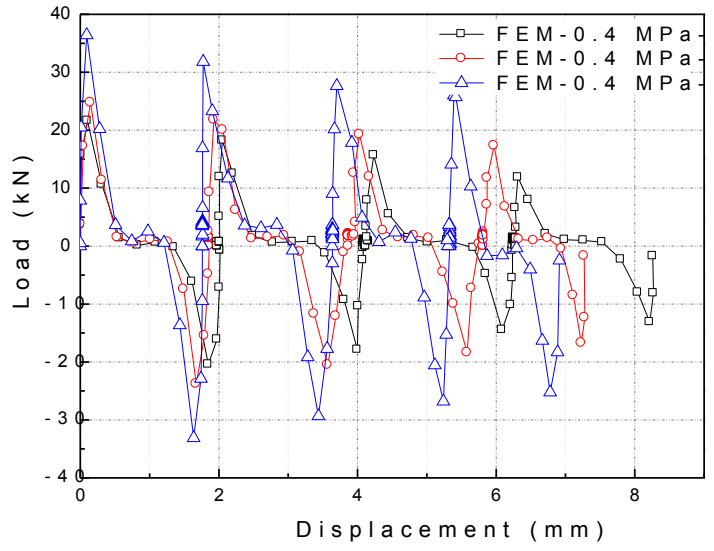

(b)

Figure 6: Load- displacement curves under 0.4MPa for (a) Experiment (b) FEM

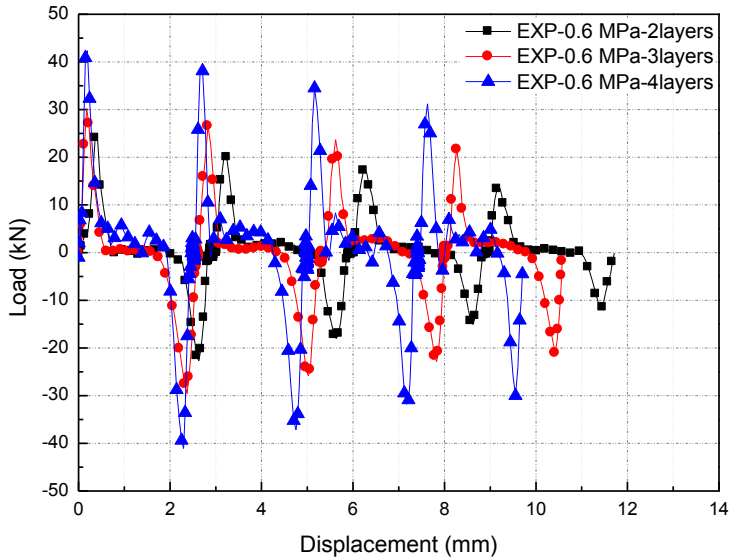

(a)

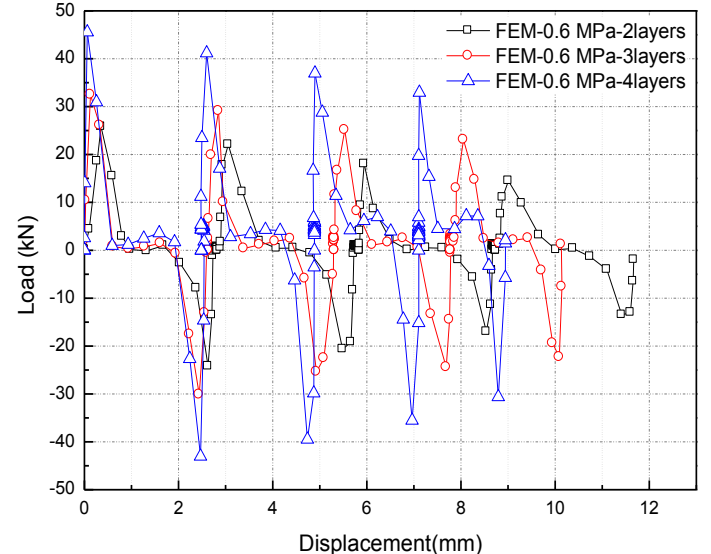

(b)

Figure 7: Load- displacement curves under 0.4MPa for (a) Experiment (b) FEM 


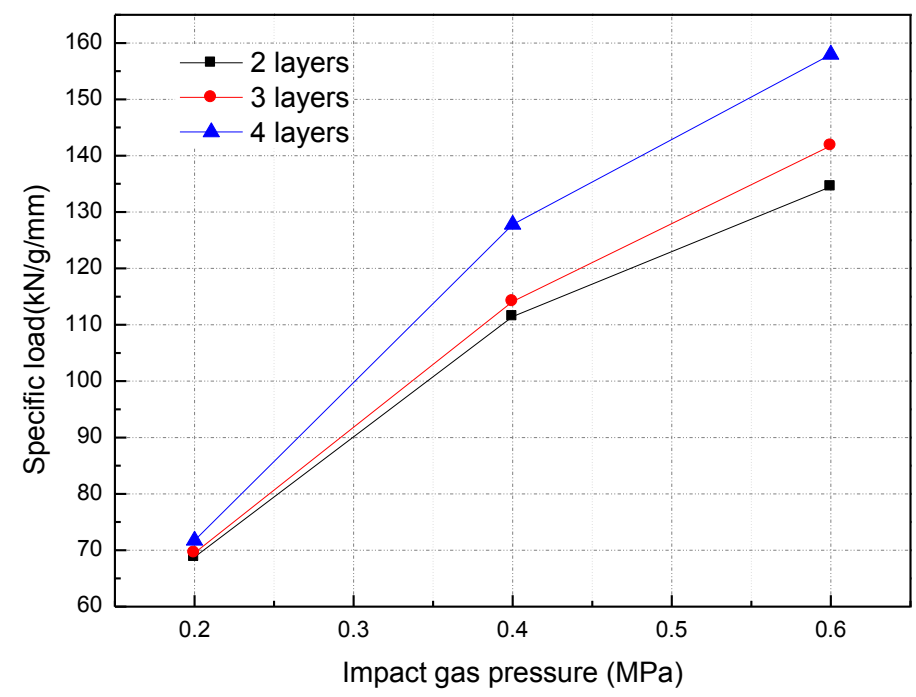

Figure 8: Specific load as a function of impact gas pressures

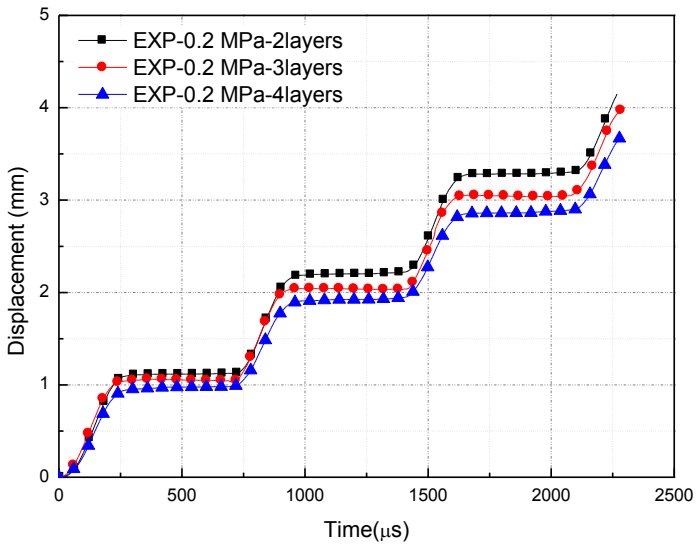

(a)

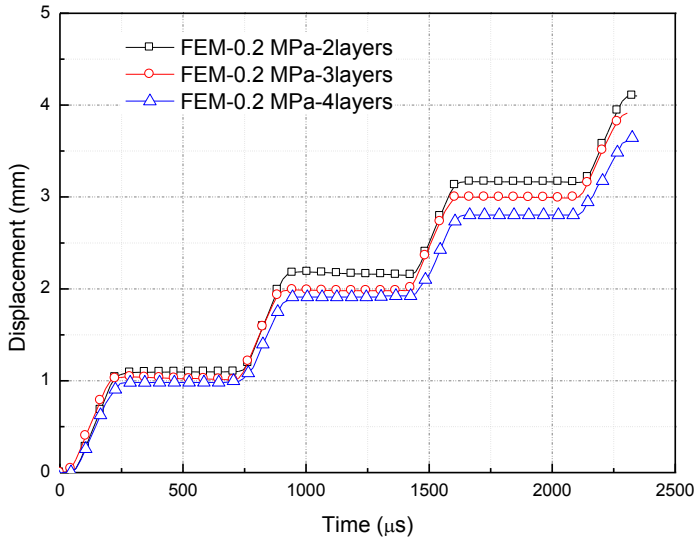

(b)

Figure 9: Displacement-time curves under 0.2MPa for (a) Experiment (b) FEM

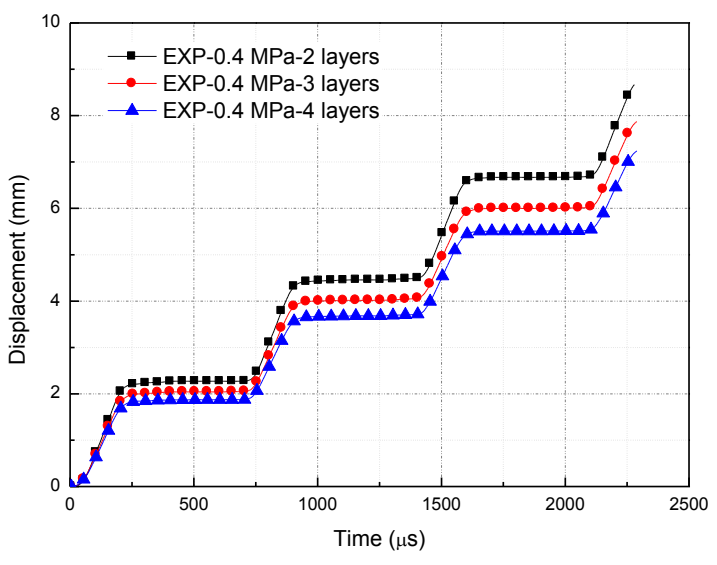

(a)

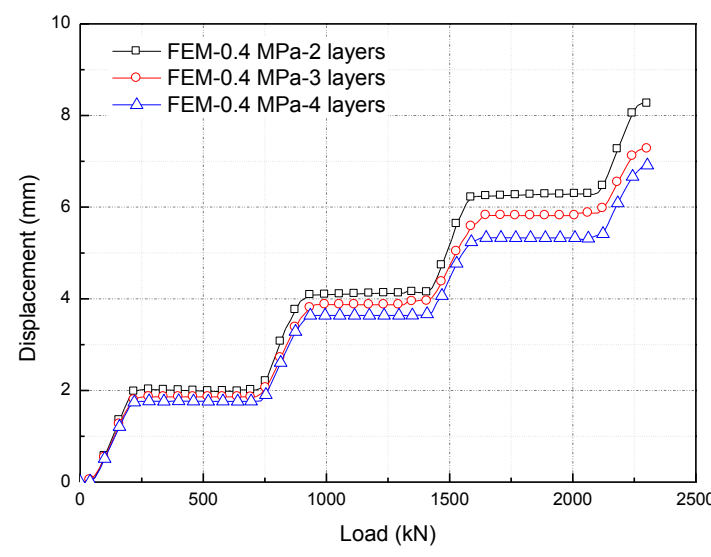

(b)

Figure 10: Displacement-time curves under 0.4MPa for (a) Experiment (b) FEM 


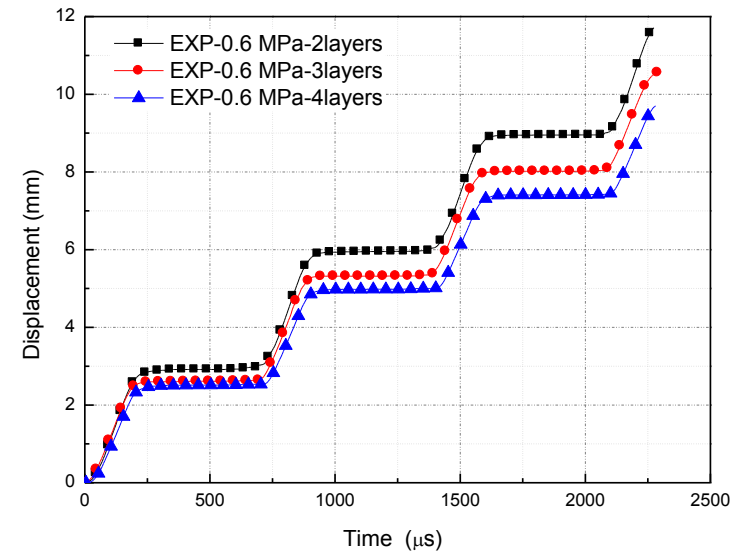

(a)

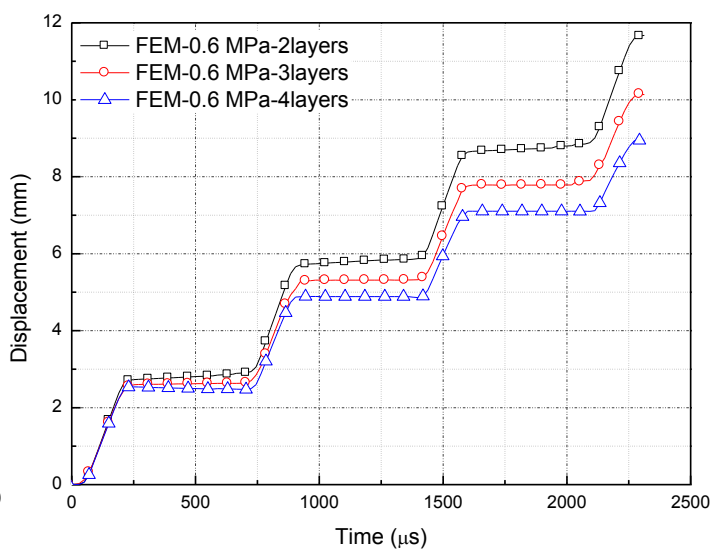

(b)

Figure 11: Displacement-time curves under 0.6MPa for (a) Experiment (b) FEM

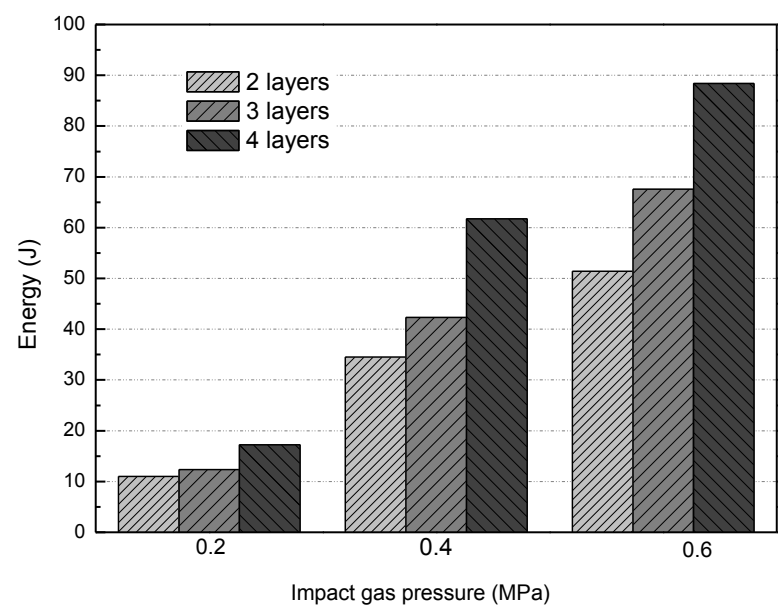

Figure 12: Energy absorption under different gas pressures 


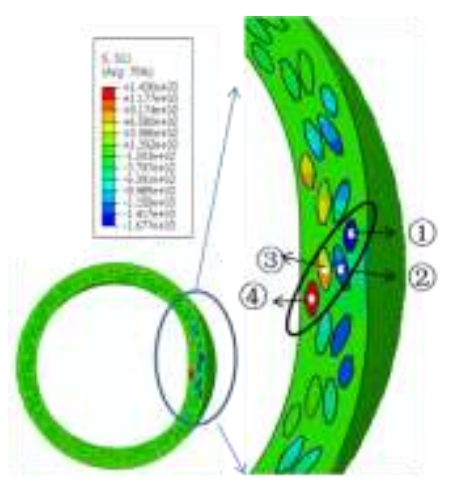

2 Layers

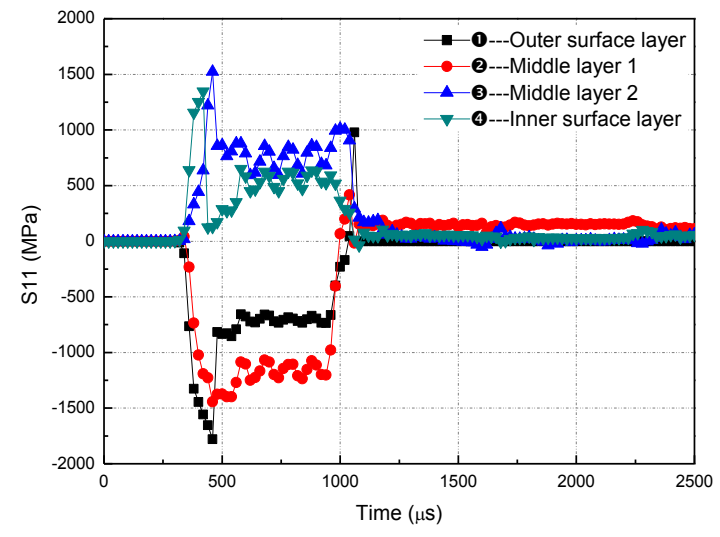

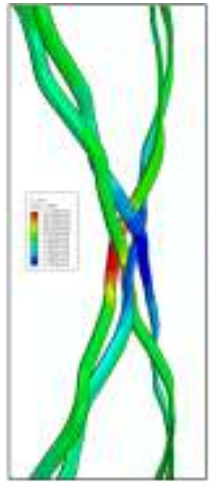

Time: $400 \mu \mathrm{s}$

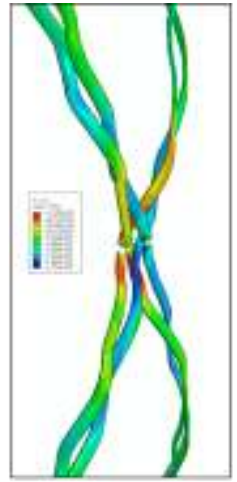

$500 \mu \mathrm{s}$

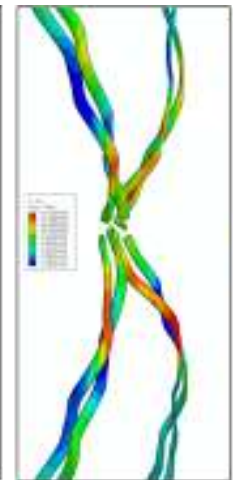

$1100 \mu \mathrm{s}$

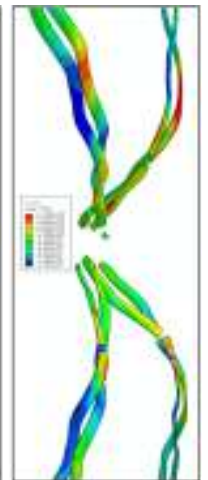

$1700 \mu \mathrm{s}$

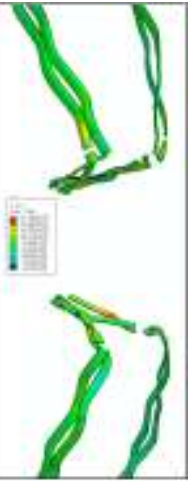

$2300 \mu$ s

(a)
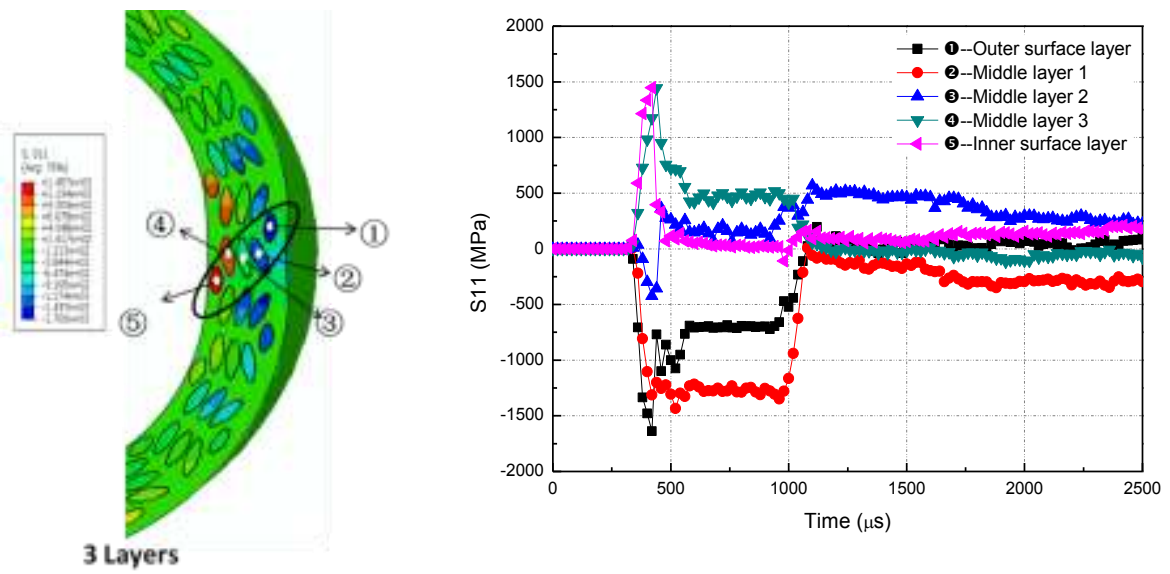

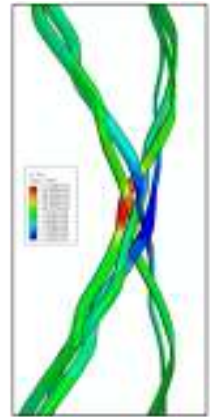

Time: $400 \mu \mathrm{s}$

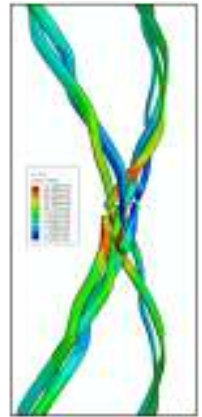

$500 \mu \mathrm{s}$

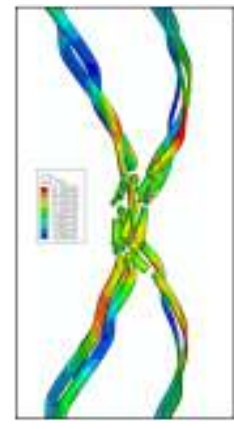

$1100 \mu \mathrm{s}$

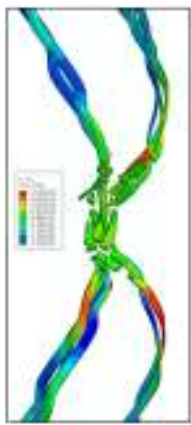

1700 us

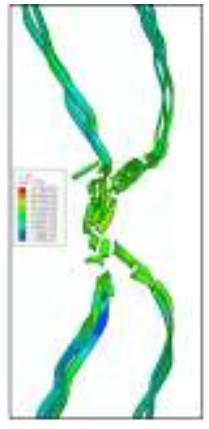

$2300 \mu \mathrm{s}$

(b) 

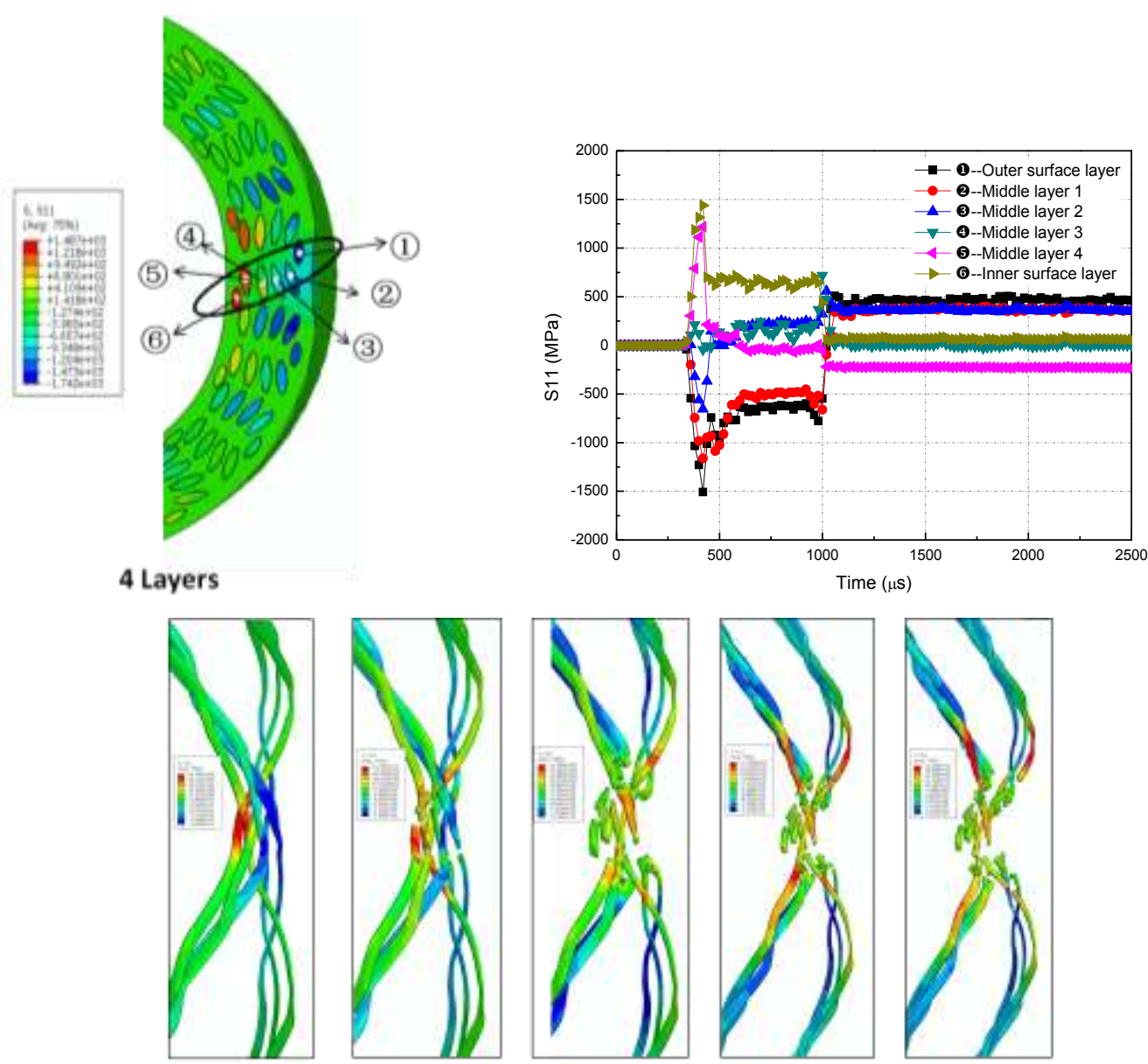

Time: $400 \mu \mathrm{s}$

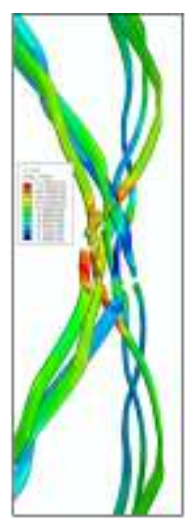

$500 \mu \mathrm{s}$

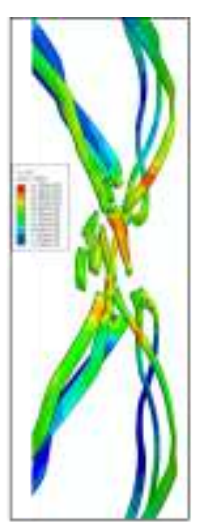

$1100 \mu \mathrm{s}$

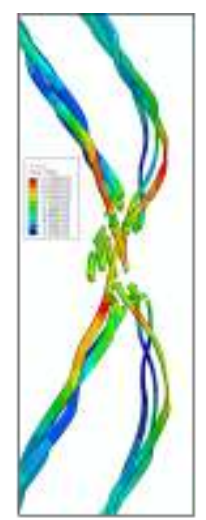

$1700 \mu \mathrm{s}$

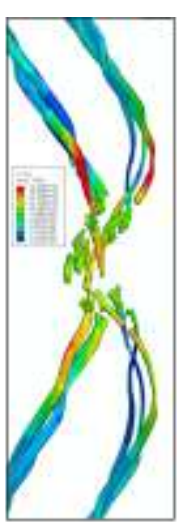

$2300 \mu \mathrm{s}$

(c)

Figure 13: Yarn stress distribution at the point of impact

(a) 2 layers, (b) 3 layers, (c) 4 layers 


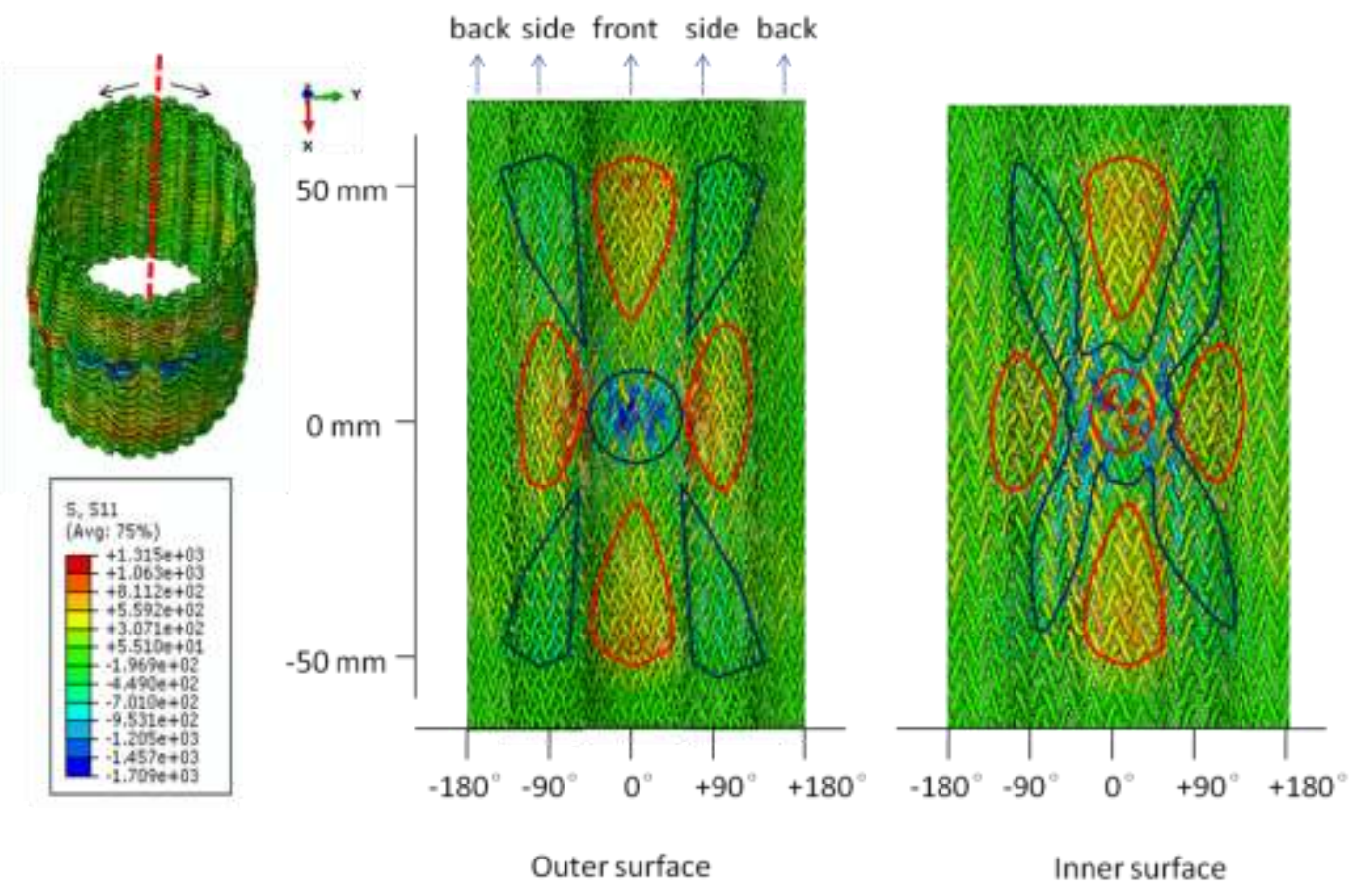

(a)

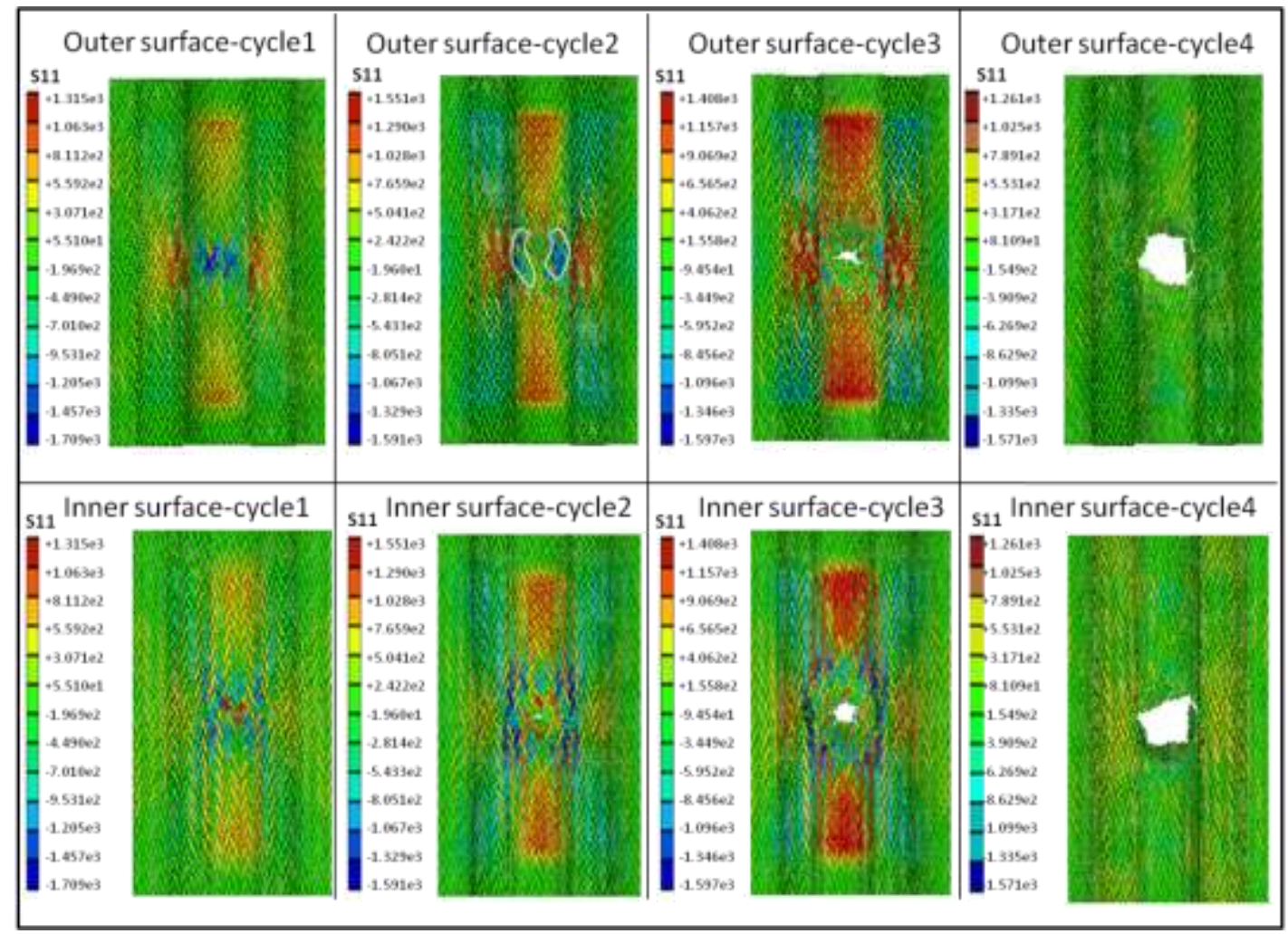

(b)

Figure 14: Stress distribution along the tube specimen under 0.2 MPa impact pressure 


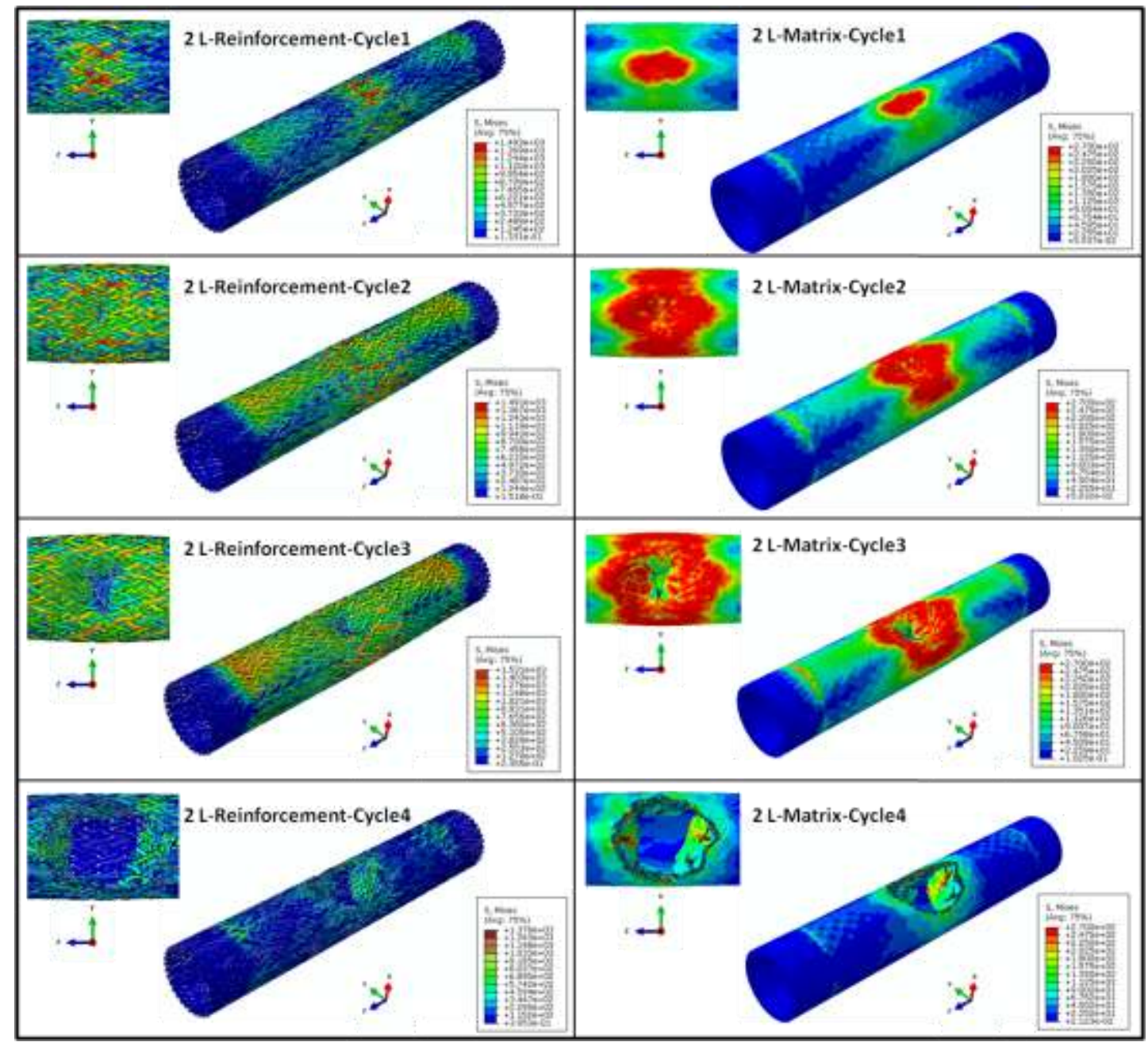

(a) 


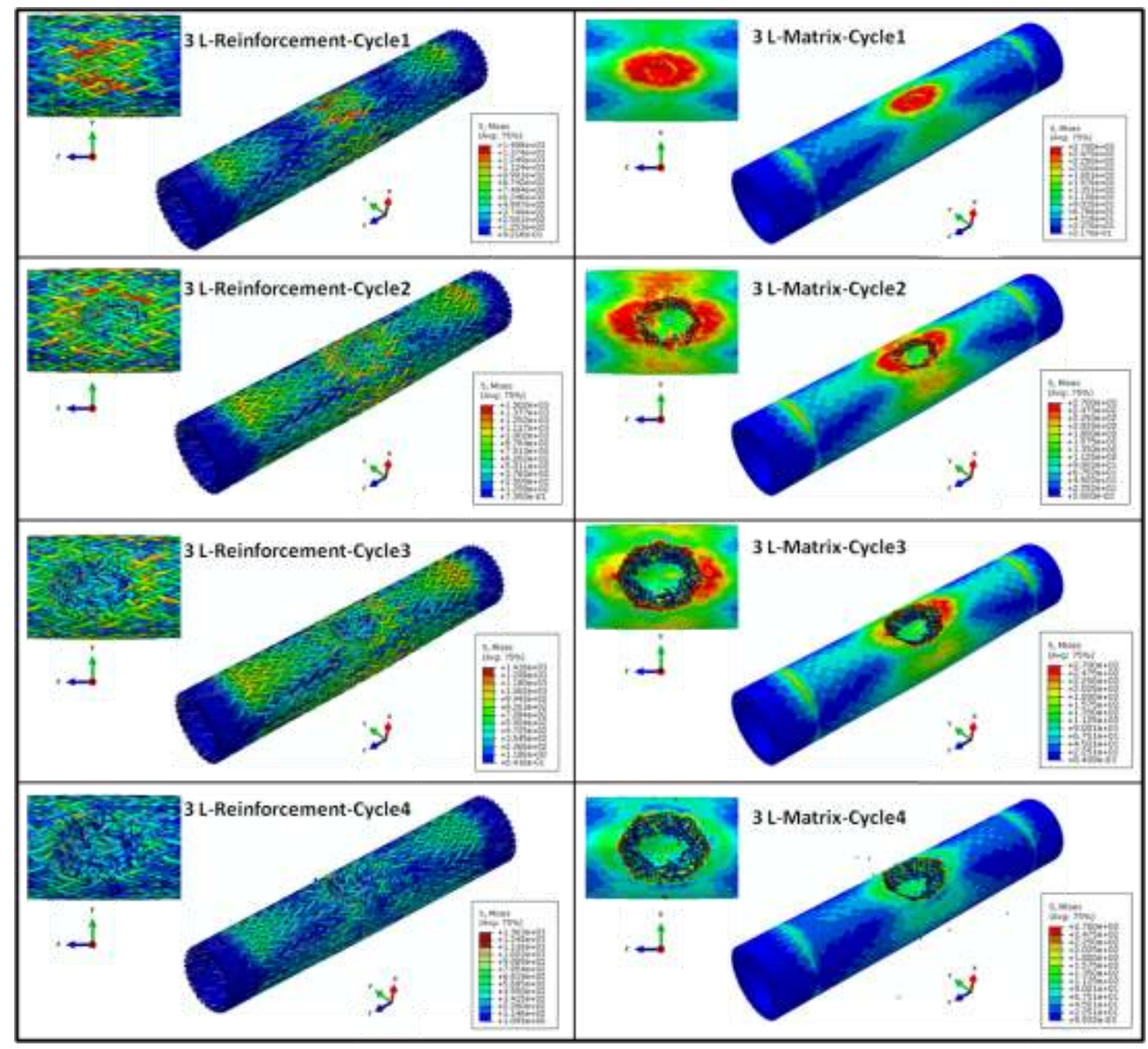

(b) 


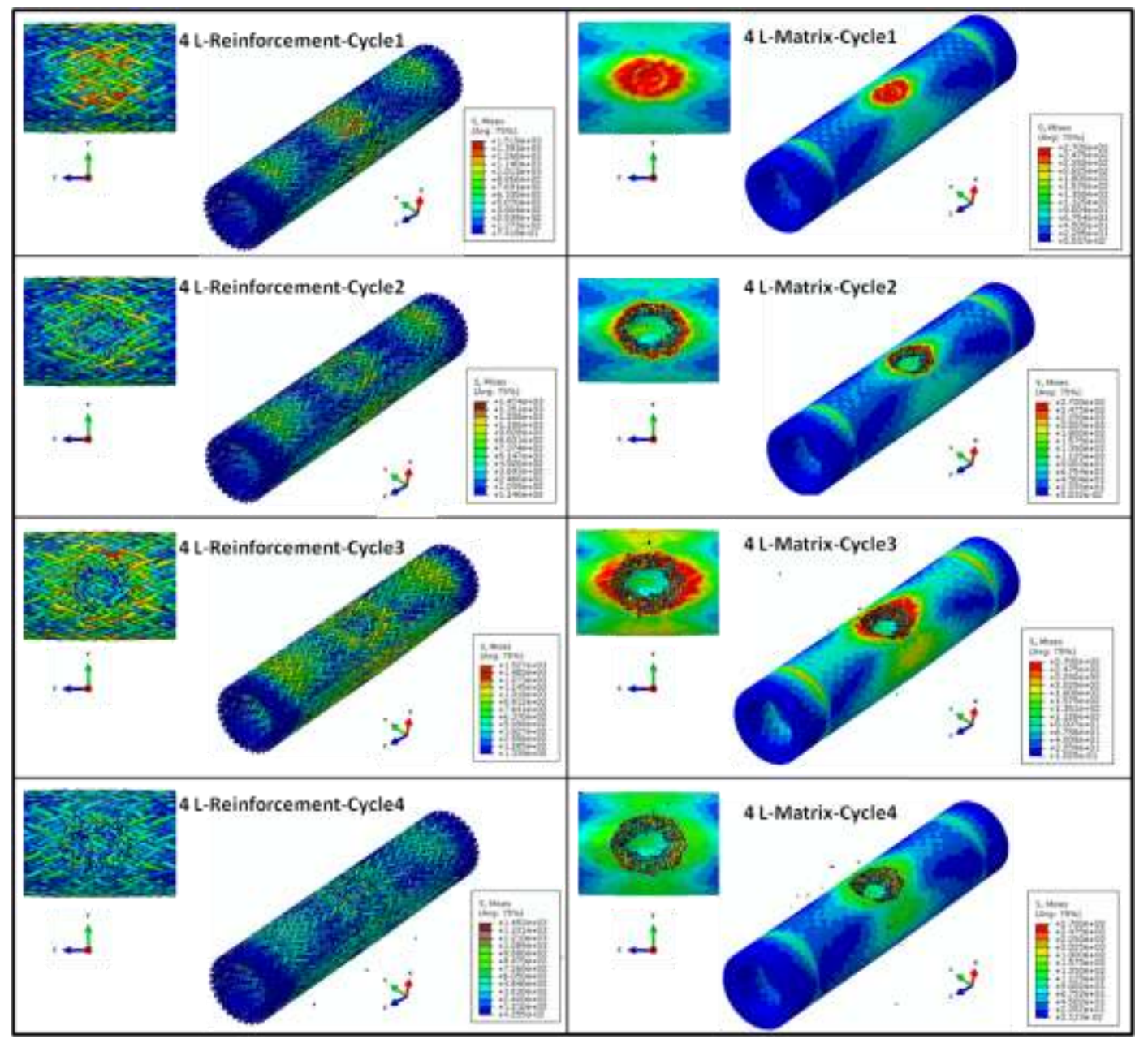

(c)

Figure 15: Damage progression during the four-cycle transverse impact loading (a) 2 layers, (b) 3 layers, (c) 4 layers. 


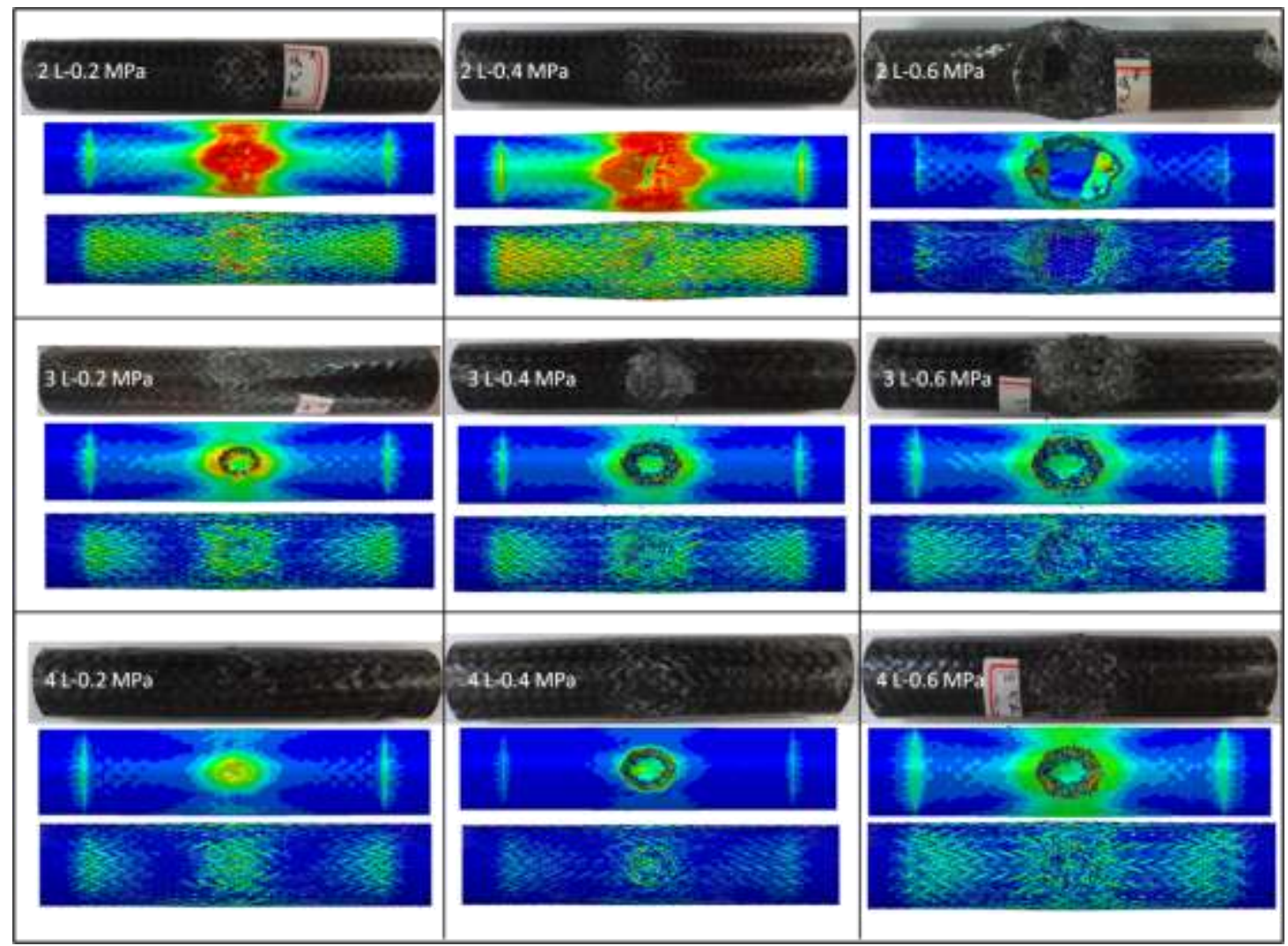

Figure 16: Comparison of damage morphology between experimental and FEA 